\title{
The Association between Functional Polymorphisms of COX-2 and Serum PGE2 Level in ESCC Patients in North of Iran
}

\author{
Maryam Sadegh Sheshpoli ${ }^{1,3}$, Safoura Khajeniazie ${ }^{2}$, Masoud Khoshnia ${ }^{3}$, Nasser Behnampour ${ }^{4}$, Mohsen Saeedi ${ }^{5}$ \\ \& Abdolvahab Moradi ${ }^{3}$ \\ ${ }^{1}$ School of New Technologies, Golestan University of Medical Sciences, Gorgan, Iran \\ ${ }^{2}$ Medical Cellular and Molecular Research Center, Golestan University of Medical Sciences, Gorgan, Iran \\ ${ }^{3}$ Golestan Research Center of Gastroenterology and Hepatology, Gorgan, Iran \\ ${ }^{4}$ Health Management and Social Development Research Center, Gorgan, Iran \\ ${ }^{5}$ Stem Cell Research Center, Golestan University of Medical Sciences, Gorgan, Iran \\ Correspondence author: Abdolvahab Moradi, Golestan Research Center of Gastroenterology and Hepatology. \\ Golestan University of Medical Sciences, Gorgan, 4934174515, Iran. E-mail: abmoradi@yahoo.com
}

Received: May 22, 2019

doi:10.5539/jmbr.v9n1p133
Accepted: September 29, 2019

Online Published: October 23, 2019

\begin{abstract}
Background: Esophageal cancer is recognized as one of the most fatal diseases around the world. Many factors are involved in the development of esophageal cancer, including genetic factors and inflammation. Cyclooxygenase-2 (COX-2) and its downstream signaling are the most important proinflammatory factors contributing to cancer. The present study aimed to evaluate the relationship between the polymorphisms and expression of COX-2 and prostaglandin-E2 (PGE2) level in patients with esophageal squamous cell carcinoma (ESCC) in Golestan Province (Iran), situated on the "esophageal cancer belt".

Methods: In this case-control study, blood and biopsy samples were obtained from ESCC patients and healthy controls. The COX-2 polymorphisms for $-1195,-1290,-765$, and +8473 SNPs were assayed using PCR-RFLP assay, while the level of PGE2 was measured using an ELISA kit. In addition, real-time PCR assay and immunohistochemistry (IHC) were performed to assay mRNA and protein expression of COX-2, respectively.

Results: An association was found between 8473TC genotype and risk of ESCC (OR=5.417, $P=0.036)$. In addition, mRNA and protein expression of COX-2 in ESCC patients was higher than the controls $(P=0.001$ and $P=0.048$, respectively). Based on the findings, the level of PGE-2 was significantly higher in ESCC patients, compared to the controls $(P=0.045)$. However, ROC curve analysis revealed PGE2 is a weak biomarker for diagnosis of ESCC. There was a significant relationship between the level of PGE2 and 8473CC, 8473TC, -765CC, and -1290AA genotypes ( $P=0.028, P=0.022, P=0.024$, and $P=0.011$, respectively).

Conclusion: Based on our results, functional polymorphisms of COX-2 (8473CC, 8473TC, - 765CC, and -1290AA) increase PGE2 level and carriers of these polymorphisms might be more susceptible to ESCC.
\end{abstract}

Keywords: Cyclooxygenase-2, Prostaglandin-E2, Esophageal cancer

\section{Introduction}

Cancer is one of the most important health issues and one of the most important reasons of death worldwide (Bab et al., 2018). It is caused by the uncontrolled generation of the abnormal cells (Alkhatib et al., 2017) that results in malignant growth, and eventually severe morbidity and mortality (Alshammari, 2018). Despite steps taken to improve knowledge regarding cancer, the burden of cancer is still rising at a great rate worldwide (Sundus at al., 2018; Abdel-Sattar et al., 2018). Esophageal cancer is a major global health concern and the sixth most common cause of cancer death. (Smyth et al., 2017) There are two subtypes of esophagus cancer (EC) with respect to cellular morphology, including squamous cell carcinoma (SCC) and adenocarcinoma.(Zhi, Zhang, Hu, Lu, \& Wang, 2003) Generally, inflammation is a response of the immune system to infection, injury, and cancer. It has been defined as "the succession of changes which occurs in a living tissue when it is injured provided that the injury is not of such a degree as to at once destroy its structure and vitality" or "the reaction to injury of the living microcirculation and related tissues" (Hemashree \& Thangavelu, 2018). COX-2 enzyme is one of the most important factors involved in inflammation.(Greenhough,Smartt,Moore, Roberts, Williams \& Cancer, 2009)This 
enzyme is not normally expressed in most tissues, although it is instantly induced by intra- and extracellular stimuli, including tumor necrosis factor (TNF), lipopolysaccharide (LPS), epidermal growth factor (EGF), interleukin-1 (IL1), transforming growth factor-alpha (TGF- $\alpha$ ), and arachidonic acid. (Whitehead \& Crawford, 2005)

Arachidonic acid is released from the plasma membrane due to cytoplasmic phospholipase- $\mathrm{A}_{2}\left(\mathrm{cPLA}_{2}\right)$ enzyme activity.(Greenhough, Smartt, Moore, Roberts, Williams \& Cancer, 2009) It acts as a stimulator (Williams, Mann and Dubois, 1999) and a substrate for COX-2 and leads to the production of prostaglandins.(Greenhough, Smartt, Moore, Roberts, Williams \& Cancer, 2009) Among prostaglandins, prostaglandin-E2 (PGE2) is involved in the effects of COX-2 on the human body. (Lowry, Reynolds, \& Cathcart, 2014) PGE2 acts through four receptors (EP1-EP4) and c AMP/PKA/CREB signaling pathway (Kalinski \& Alerts, 2012) and is primarily involved in inflammation and cancer. (Lowry, Reynolds, \& Cathcart, 2014)

The levels of COX-2 and PGE2 expression have been shown to increase in many tumors, (Lowry, Reynolds, \& Cathcart, 2014) and even PGE2 has been introduced as a contributing factor for carcinogenesis (Morgan, 1997) via induction of cell proliferation, resistance to apoptosis, and angiogenesis.(Yu,Wu,Li,Wong,Tai, \& Li, 2008; Kuo,Wang,Chou, Hsu, Hsu, Lin,\& Wang, 2009; Hu et al., 2016) However, PGE2 cannot use as a diagnostic marker, as it increases in the early stages of esophageal cancer and then decreases. (Diakowska et al., 2014)

COX-2 gene is located on chromosome 1q25.2-q25.3 and includes 10 exons.(Ryushi Tazawa, Xiao-Ming, no date) The COX-2 promoter contains regulatory elements, such as stimulatory protein-1 (SP1).(Kosaka et al., 1994) The -765CC genotype has been identified in the binding site of SP1,(Expression et al., 2002) increasing COX-2 expression and prostaglandin production. (Szczeklik, Sanak, \& Szczeklik, 2004)

On the other hand, the COX-2 -1195GA genotype generates a c-MYB binding site and up regulates COX-2 expression.(Zhang, Miao, Tan, Ning, Liu, \& Hong, 2005) Moreover, the $+8473 \mathrm{~T}>\mathrm{C}$ genotype, which is located on 3'-UTR of COX-2 gene, can change COX-2 expression through affecting mRNA stability and translation. (J $\&$ R, 2001; Liu et al., 2017)

The COX-2 $-1290 \mathrm{~A}>\mathrm{G}$ genotype also has functional effect.(Zhang, Miao, Tan, Ning, Liu, \& Hong, 2005) Genetic variations of COX-2 gene can change its expression and result in prostaglandin production, inflammation, and tumor development.(Fritsche et al., 2001) Therefore, detection of the genetic profile of COX-2 can help develop appropriate treatments for patients with ESCC.(Tazawa\&Ming, no date)

In this case-control study, we selected 4 variants of COX-2 gene (rs689465, rs689466, rs20417, and rs5275), based on their relevance and involvement in cancer. (Zhang, Miao, Tan, Ning, Liu, \& Hong, 2005; Liu et al., 2006; Upadhyay et al., 2009; Liang et al., 2011) These COX-2 polymorphisms were selected to evaluate susceptibility to ESCC in North of Iran. Also, mRNA and protein expression was evaluated in tumor and adjacent normal tissues. Then, the association between COX-2 polymorphisms (-1290, -1195, -765, and 8473) and COX-2 expression was analyzed. In addition, PGE-2 concentration was measuredin the serum of ESCC patients and healthy controls, and the relationship between COX-2 polymorphisms $(-1290,-1195,-765$, and 8473$)$ and serum level of PGE-2 was analyzed.

\section{Materials and Methods}

\subsection{Sample Collection}

In this case-control study, sampling was carried out before any treatment among ESCC patients and healthy individuals, who were referred to Hospital during 2015-2017. Half of the blood volume was transferred to tubes containing EDTA and kept at $-20^{\circ} \mathrm{C}$ until DNA extraction for the PCR-RFLP assay. The other half of the blood volume was poured in tubes without EDTA for serum separation. The collected sera were stored at $-20^{\circ} \mathrm{C}$ until PGE2 assay. Also, biopsy was taken from the tumor and normal adjacent esophageal tissues $(5 \mathrm{~cm}$ from the tumor margins). A section of the biopsy was stored in RNA-later solution and kept at $-80^{\circ} \mathrm{C}$ until RNA extraction for Real Time-PCR, and the other section was embedded in the paraffin for COX2 protein assay in the IHC test.

\subsection{Single-Nucleotide Polymorphism (SNP) Analysis}

\subsubsection{COX-2 Genotyping}

We investigated four SNPs, namely, $-1195 \mathrm{G}>\mathrm{A},-1290 \mathrm{~A}>\mathrm{G},-765 \mathrm{G}>\mathrm{C}$, and $+8473 \mathrm{~T}>\mathrm{C}$, in 50 ESCC patients and 30 healthy controls. To evaluate these polymorphisms, PCR-restriction fragment length polymorphism (PCR-RFLP) technique was applied. A DNA extraction kit was used for extracting DNA from peripheral blood lymphocytes, and PCR was performed by specific primers (Table 1). (Zhang, Miao, Tan, Ning, Liu, \& Hong, 2005; Wu et al., 2011; Dai, Wu, \& Li, 2015) The PCR reaction mixture $(25 \mu \mathrm{l})$ consisted of $0.6 \mu \mathrm{M}$ of each primer 
(10pmol), 100ng of genomic DNA, and $12.5 \mu$ of Taq DNA Polymerase 2X Master Mix. For digestion, a proper restriction enzyme was used to incubate the PCR products at $37^{\circ} \mathrm{C}$ for three hours (Table 1). (Hu et al., 2005; Zhang, Miao, Tan, Ning, Liu, \& Hong, 2005; Dasdemir et al., 2013) The PCR products before and after digestion were run on gel electrophoresis to detect the size of DNA fragments. Some PCR products were sequenced to confirm the PCR-RFLP results.

Table1. The PCR-RFLP assay using specific primers

\begin{tabular}{|c|c|c|c|c|}
\hline Gene(SNP ID) & primer Sequence & $\begin{array}{l}\text { Restriction } \\
\text { Enzyme }\end{array}$ & $\begin{array}{l}\text { PCR Product } \\
\text { size }(b p)\end{array}$ & $\begin{array}{l}\text { DNA fragments size } \\
\text { (bp) }\end{array}$ \\
\hline 1195 (rs689466) & $\begin{array}{l}\text { F: CCCTGAGCACTACCCATGAT } \\
\text { R: GCCCTTCATAGGAGATACTGG }\end{array}$ & Pvu II & 273 & $220+53$ \\
\hline $1290($ rs689465) & $\begin{array}{l}\text { F: CAGGTTTTATGCTGTCATTTTCC } \\
\text { R: TAGTGCTCAGGGAGGAGCAT }\end{array}$ & Rsa I & 174 & $121+52$ \\
\hline 765 (rs20417) & $\begin{array}{l}\text { F: TATTATGAGGAGAATTTACCTTTCCC } \\
\text { R: GCTAAGTTGCTTTCAACAGAAGAAAT }\end{array}$ & Acil & 100 & $74+26$ \\
\hline 8473 (rs5275) & $\begin{array}{l}\text { F: GTTTGAAATTTTAAAGTACTTTTGAT } \\
\text { R: TTTCAAATTATTGTTTCATTGC }\end{array}$ & $\mathrm{Bcl} \mathrm{I}$ & 147 & $124+23$ \\
\hline
\end{tabular}

\subsection{PGE2 Assay}

The concentration of PGE-2 in the serum was measured using an ELISA kit (Abnova, KA0326). The sensitivity of this assay for PGE-2 measurement has been estimated at $30.9 \mathrm{pg} / \mathrm{ml}$. (Diakowska et al., 2014)

\subsection{Real Time-PCR Assay}

For extraction of total RNA from tumor and normal tissues, Trizole reagent (Invitrogen) was used. We applied 1 $\mu$ gof total RNA (A260/A280 ratio, 1.6/2.0) from each sample for the synthesis of first-strand cDNA, using oligo (dT) and random hexamer primers. Then, the RT product was used as a template for amplification of specific fragments by specific primers (Table2). (Zhang, Miao, Tan, Ning, Liu, \& Hong, 2005; Bhandari et al., 2006; Sommerfelt et al., 2015) The expression of COX-2 was measured relative to the expression of GAPDH gene as the internal control gene in tumor and normal tissues, using the $2^{-\Delta \Delta C t}$ formula. (Schmittgen \& Livak, 2008)

A sequence detection system (ABI Prism 7300, Applied Biosystems) was used to quantitate the levels of COX-2 and GAPDH expression, based on the SYBR-Green method. The PCR reaction mixture consisted of $0.5 \mu 1$ of each primer (Table 2), 2X qPCR Master Mix Green (High Rox ${ }^{\mathrm{TM}}$ ), and 100ng of complementary DNA in a final volume of 25ML. (Zhang, Miao, Tan, Ning, Liu, \& Hong, 2005; Bhandari et al., 2006) The PCR conditions for each gene were optimized, and the cycling conditions included 15 minutes of primary denaturation at $95^{\circ} \mathrm{C}$, followed by 40 cycles for 15 seconds at $95^{\circ} \mathrm{C}$ and annealing for one minute at $60^{\circ} \mathrm{C}$.

Table2. Specific primers for the RT-PCR assay

\begin{tabular}{llll}
\hline Gene & Forward Primer sequences 5'- 3' $^{\prime}$ & Reverse Primer sequences 5'- 3' $^{\prime}$ & Product size \\
\hline COX-2 & GGGGATCAGGGATGAACTTT & TGGCTACAAAAGCTGGGAA & 172 \\
GAPDH & CATCAAGAAGGTGGTGAAGCAG & TGTAGCCAAATTCGTTGTCATACC & 191 \\
\hline
\end{tabular}

\subsection{Immunohistochemistry Staining}

The esophageal tissue specimens were processed in a tissue processor using conventional procedures, and paraffin blocks were prepared. After cutting the blocks into $4 \mathrm{~mm}$ sections, they were mounted on poly lysine-coated slides and dewaxed in xylene. Following that, they were rehydrated in a descending series of alcohols and blocked for 10 minutes, using hydrogen peroxide in methanol for endogenous peroxidase. Overnight incubation was performed on the slides at $4^{\circ} \mathrm{C}$ using Ptgs 2 monoclonal antibodies, clone SP1 (MAB2149, Abnova, Taiwan). Then, the slides were incubated at $25^{\circ} \mathrm{C}$ with goat anti-rabbit IgG secondary antibody (Santa Cruz Biotechnology, MA, USA) for one hour. Immunostaining was performed based on horseradish peroxidase (HRP) technique. The samples were visualized by the EnVision method (Dako, Denmark), as recommended by the manufacturer. The sections were similarly treated for the negative control, but without the primary antibodies. 
Expression of COX-2 was determined semi-quantitatively relative to positive cancer cell percentage. Classification of staining intensity was as follows: none (0), poor (1), moderate (2), and strong (3). In addition, the percentage of positive cancer cells was categorized as follows: $0(0 \%), 1(1-10 \%), 2(11-49 \%)$, and 3 (50-100\%). Overall, grades 0 and 1 are indicative of low expression, while grades 2 and 3 represent high levels of expression. (Cui, Dong, Wu, Duan, Shi, \& Gong, 2015)

\subsection{Statistical Analysis}

For data analysis, SPSS version 16 was used. To evaluate the effects of polymorphisms on ESCC, Fisher's exact test was applied. Moreover, Mann-Whitney test was performed to determine the relationship between COX-2 polymorphisms and PGE2 concentration. COX-2 expression was determined using one sample $t$ test in the RT-PCR method and Fisher's exact test in the IHC method. The significance level was set at $P<0.05$.

\section{Results}

\subsection{PCR-RFLP Assay}

The effects of polymorphisms on ESCC were examined based on Fisher's exact test. No significant association was found between polymorphisms (-1195, -1290, and -765) and ESCC, as confirmed by the logistic regression analysis. However, significant association was found between 8473TC genotype and risk of ESCC (OR= 5.417; $95 \% \mathrm{CI}, 1.115-26.310 ; P=0.036$ ). Therefore, it is possible for $8473 \mathrm{TC}$ carriers to be more susceptible to ESCC (Table 3).

Table 3. The relationship between COX-2 polymorphisms and risk of ESCC based on the genotypes

\begin{tabular}{|c|c|c|c|c|c|c|}
\hline \multirow{2}{*}{ Genotype } & \multicolumn{2}{|c|}{$\operatorname{ESCC}(\mathrm{N}=50)$} & \multicolumn{2}{|c|}{ Control(N=30) } & \multirow{2}{*}{$\begin{array}{l}\text { P-value(for genotype } \\
\text { frequency) }\end{array}$} & \multirow{2}{*}{$(\mathrm{OR}),(95 \% \mathrm{CI}),(\mathrm{P}-$ value for $\mathrm{OR}$} \\
\hline & Number & Percent & Number & Percent & & \\
\hline \multicolumn{7}{|l|}{$-1195 \mathrm{G}>\mathrm{A}$} \\
\hline GG & 33 & $(66)$ & 22 & $(73.3)$ & \multirow{3}{*}{$>0.824$} & \multirow{2}{*}{$\begin{array}{l}\text { Reference } \\
(1.429),(0.501-4.07),(0.504)\end{array}$} \\
\hline GA & 15 & $(30)$ & 7 & $(23.3)$ & & \\
\hline AA & 2 & (4) & 1 & (3.3) & & $(1.333),(0.114-15.612),(0.819)$ \\
\hline \multicolumn{7}{|l|}{$-1290 \mathrm{~A}>\mathrm{G}$} \\
\hline AA & 40 & $(80)$ & 24 & $(80)$ & \multirow{3}{*}{$>0.824$} & \multirow{3}{*}{$\begin{array}{l}\text { Reference } \\
(0.96),(0.282-3.273),(0.948) \\
(1.2),(0.103-13.951),(0.884)\end{array}$} \\
\hline $\mathrm{AG}$ & 8 & (16) & 5 & $(16.7)$ & & \\
\hline GG & 2 & (4) & 1 & (3.3) & & \\
\hline \multicolumn{7}{|l|}{$-765 \mathrm{G}>\mathrm{C}$} \\
\hline GG & 34 & $(68)$ & 19 & $(63.3)$ & \multirow{3}{*}{0.418} & \multirow{3}{*}{$\begin{array}{l}\text { Reference } \\
(2.794),(0.304-25.706),(0.364) \\
(0.615),(0.221-1.711),(0.352)\end{array}$} \\
\hline $\mathrm{GC}$ & 5 & $(10)$ & 1 & (3.3) & & \\
\hline $\mathrm{CC}$ & 11 & $(22)$ & 10 & $(33.3)$ & & \\
\hline \multicolumn{7}{|l|}{$8473 \mathrm{~T}>\mathrm{C}$} \\
\hline $\mathrm{TT}$ & 30 & $(60)$ & 25 & $(83.3)$ & \multirow{3}{*}{0.056} & \multirow{3}{*}{ 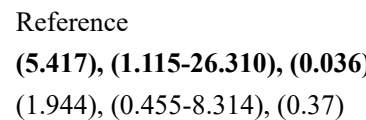 } \\
\hline $\mathrm{TC}$ & 13 & (26) & 2 & (6.7) & & \\
\hline $\mathrm{CC}$ & 7 & (14) & 3 & (10) & & \\
\hline
\end{tabular}

*Significant values are shown in bold. $95 \%$ CI: $95 \%$ confidence interval. OR: odds ratio

\subsection{PGE2 Assay}

We used nonparametric Mann-Whitney test to compare PGE2 concentration between ESCC patients and healthy controls. The PGE2 concentration is presented as mean \pm SE (1084.77 \pm 94.46 vs. $790.28 \pm 121.81 \mathrm{pg} / \mathrm{ml})$. Based on the findings, the PGE2 level was significantly higher in ESCC patients in comparison with the controls $(P=$ 0.045) (Figure 1). 


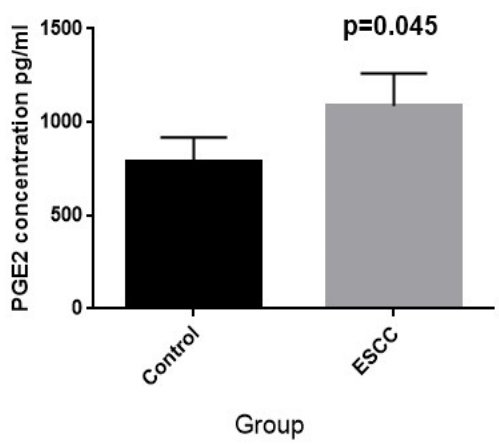

Figure1. Comparison of PGE2 concentration in serum between ESCC patients and control groups

*The groups were significantly different regarding the mean PGE2 concentration $(\mathrm{P}=0.045)$.

\subsubsection{ROC Curve Analysis}

ROC curve analysis showed Area under the curve for PGE2 was 0.671 and in cut off point $=1127$, sensitivity and specificity were $59 \%$ and $77 \%$, respectively. Therefore, PGE2 is a weak diagnostic marker for ESCC (Figure 2).

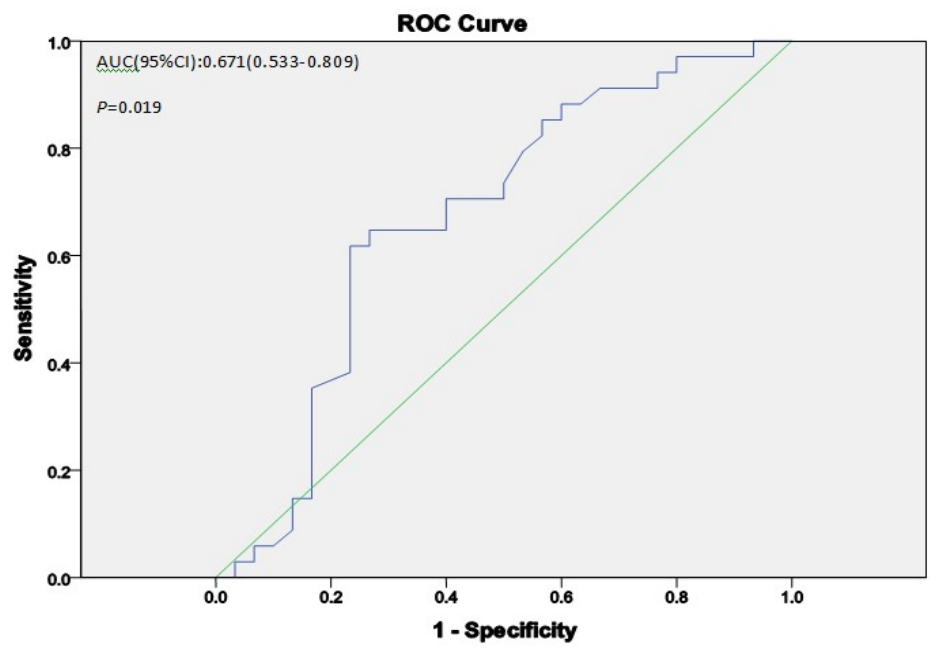

Figure 2. ROC curve for evaluating of PGE2 as diagnostic marker

* PGE2 is a weak diagnostic marker for ESCC (AUC=0.671, $P=0.019$ ).

We used Mann-Whitney test for comparing the mean PGE2 concentration in 1195, 1290, 765 and 8473 alleles from ESCC patients and controls with the same genotype. The findings did not indicate a significant association between 1195 genotypes and PGE2 concentration. However, a significant association was found between 1290AA, 765CC, 8473TC and 8473CC genotype and PGE2 concentration $(P=0.011, P=0.024, P=0.022$, and $P=0.028$, respectively).

\subsection{RT-PCR Results}

In this study, COX-2 expression was upregulated in $80 \%$ patients in comparison with the controls. Based on one sample $t$ test, the groups were significantly different with respect to relative COX-2 expression (mean $\pm \mathrm{SE}=$ $9.51 \pm 2.42,95 \% \mathrm{CI}=4.54-14.48, P=0.00 .1)$ (Figure3). However, COX-2 polymorphisms $(-1195,-1290,-765$, and +8473$)$ were associated with increased COX2 mRNA level; however, the association did not show a statistically significant. 


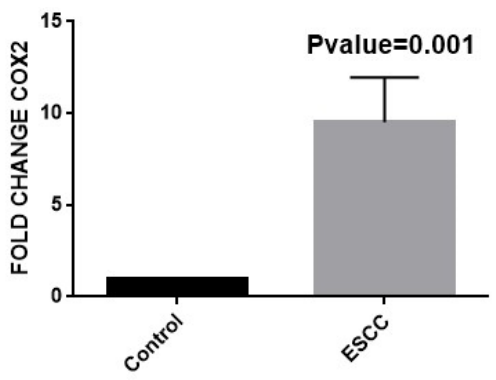

Figure3. The fold change of COX-2 expression in ESCC and control groups

COX-2 expression was found to increase significantly $(P=0.001)$.

\subsection{IHC Results}

The IHC results were examined using Fisher's exact test. COX-2 proteins were observed in $73 \%$ patients. COX-2 immunoreactivity was characteristically in cytoplasm. Based on the findings, tumor and normal tissues were significantly different regarding the level of COX-2 protein $(P=0.048)$ (Figure 4).

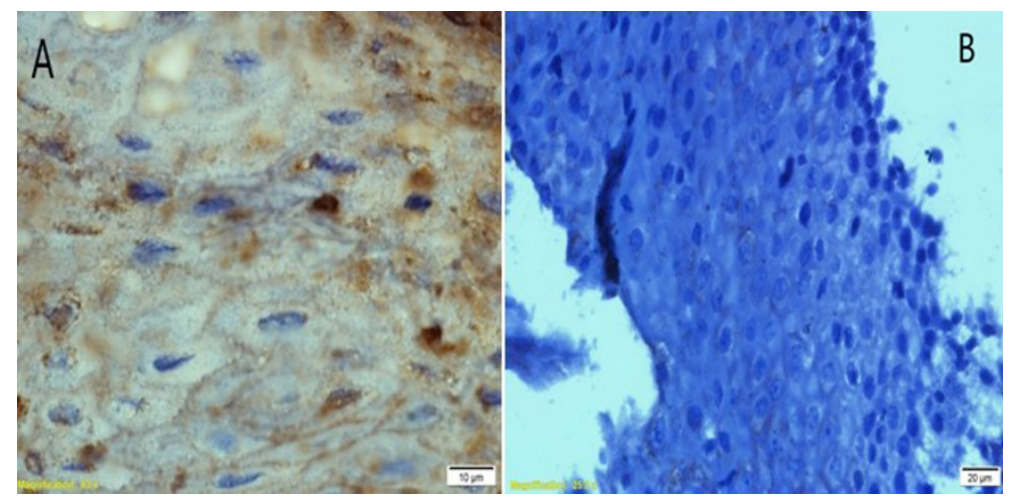

Figure 4. A (left): IHC staining of positive COX-2 protein in a tumor tissue; and B (right): IHC staining of negative COX-2 protein in a normal tissue

\section{Discussion}

In our study, we investigated some COX-2 SNPs, including $-765 \mathrm{G}>\mathrm{C},-1195 \mathrm{G}>\mathrm{A},-1290 \mathrm{G}>\mathrm{A}$, and $+8473 \mathrm{~T}>\mathrm{C}$, in ESCC patients and healthy individuals in North of Iran. We found an association between 8473TC genotype and ESCC $(\mathrm{OR}=5.417 ; \% 95 \mathrm{CI}, 1.115-26.310 ; P=0.036)$. Regarding the allelic frequency, 8473TC and CC genotypes of COX-2 gene could increase COX-2 expression and prostaglandin production; therefore, these genotypes might be more susceptible to ESCC.

Conversely,(Hu et al., 2005) in a study on a Chinese population reported that $8473 \mathrm{TC}$ and $\mathrm{CC}$ genotypes played protective roles in lung cancer. The frequency of TT, TC, and CC genotypes was $72.7 \%, 25.8 \%$, and $1.6 \%$, respectively, while in our study, the corresponding frequencies were $60 \%, 26 \%$, and $14 \%$, respectively. It seems that similar genotypes generate different phenotypes in different tissues.

In addition, Upadhyay $R$ et al. (2009) showed that $-1195 \mathrm{G}>\mathrm{A},-1290 \mathrm{~A}>\mathrm{G}$, and $3^{\prime}-\mathrm{UTR}$ 8473T $>\mathrm{C}$ polymorphisms had no significant association with ESCC, whereas $765 \mathrm{GC}$ and CC polymorphisms conferred ESCC susceptibility in an Indian population. (Upadhyay et al., 2009) In the present study, individuals carrying $765 \mathrm{GC}$ genotypes were found to be more susceptible to ESCC, which is in line with the results reported by Upadhyay $\mathrm{R}$ and colleagues. In contrast, $765 \mathrm{CC}$ genotype may be protective against esophageal cancer considering its frequency.

In agreement with our findings, Zhang et al. (2005) (Zhang, Miao, Tan, Ning, Liu, \& Hong, 2005) reported a significant relationship between -765GC genotype and increased risk of ESCC in a Chinese population, while Hoff et al. (2009) (Hoff,te Morsche,Roelofs,van der Logt,Nagengast,\& Juliët, 2009) found that 765GC genotype reduced the risk of colorectal cancer in a Dutch population. Zhang et al. (Zhang, Miao, Tan, Ning, Liu, \& Hong, 
2005 ) showed that the frequency of $765 \mathrm{GG}, \mathrm{GC}$, and $\mathrm{CC}$ genotypes was $90.6 \%, 9.4 \%$, and $0 \%$, respectively in ESCC patients. The corresponding frequencies were $58 \%, 39.7 \%$, and $2.3 \%$, in the study by Upadhyay R et al. (2009) (Upadhyay et al., 2009) on an Indian population and 68\%, 10\%, and 22\% in our study, respectively. These results show that the frequency of genotypes varies in Iranian, Indian, and Chinese populations. Therefore, in addition to genetic modifications, environmental factors and ethnic differences can also affect the disease phenotypes.

In the present study, we found a significant association between $765 \mathrm{CC}$ genotype and PGE2 level in ESCC patients. Similar to our study, W. Szczeklik et al. found a strong association between 765CC genotype and prostaglandin level in patients with asthma.(Szczeklik, Sanak, \& Szczeklik, 2004) Additionally, Huiying Zhi et al (2006) reported COX-2 mRNA overexpression in ESCC patients.(Zhi, Wang, Zhang, Zhou, Ding, \& Luo, 2006) Also, X. Liu et al. (2008) indicated COX-2 mRNA expression in 54.5\% of ESCC patients but expression was negative in the adjacent normal tissues. (Liu et al., 2008) Similarly, in our study, COX-2 mRNA expression was upregulated in $80 \%$ of patients; this increase was significantly different between the ESCC and control groups $(P=0.001)$. The COX 2 polymorphisms (i.e., $-1195 \mathrm{G}>\mathrm{A},-1290 \mathrm{~A}>\mathrm{G},-765 \mathrm{G}>\mathrm{C}$, and $8473 \mathrm{~T}>\mathrm{C}$ ) were associated with elevated COX-2 mRNA level; but the association was not significant statistically.

Our findings also revealed that PGE-2 concentration increased significantly in the serum of patients with ESCC rather than normal controls $(P=0.045)$. Also, we found that $-1195 \mathrm{G}>\mathrm{A}$ polymorphism was not associated with the serum concentration of PGE2; however PGE2 level in patients with 1290 AAgenotype was significantly different from healthy subjects with the same genotype $(P=0.011)$. The serum level of PGE2 was significantly different between ESCC patients and controls with -765 CC genotype $(P=0.024)$. The ESCC patients and controls with $8473 \mathrm{TC}$ and $\mathrm{CC}$ genotypes were found to be significantly different in terms of the serum level of PGE2 ( $P=0.022$ and 0.028 , respectively). Based on the findings, it is possible that allele $\mathrm{C}$ of $8473 \mathrm{~T}>\mathrm{C}$ and 765 $\mathrm{G}>\mathrm{C}$ genotypes more contributes to the increased concentration of PGE2 in ESCC patients.

Furthermore, Fawzy et al. (2013) reported that PGE2 level increases significantly in patients with breast cancer carrying 8473CC genotypes (Fawzy et al., 2013) which is in agreement with our findings. Similar to our study, Diakowska (2014) in a study on ESCC patients (Diakowska et al., 2014)and Hambek (2007) in a study on head and neck cancer patients (Hambek et al., 2007)reported an increase in the serum PGE-2 level. However, their studies revealed that PGE2 cannot be considered an independent marker for cancer diagnosis, as it increases only in the early stages of cancer.(Hambek et al., 2007; Diakowska et al., 2014)

In our study, COX-2 protein was upregulated in $73 \%$ of ESCC patients in the cancerous area of esophagus tissues rather than the normal margins. This finding is in accordance with the results reported by Yong Cui, et al. (2015) (Yong Cui, Chang Dong, Bing-Qun Wu, Xin-Chun Duan, Guan Shi, Min Gong, 2015) and Dongxin Hu, et al. (2016).(Hu et al., 2016)

The present study revealed the association of the functional polymorphisms of COX-2 gene with COX-2 expression and PGE2 concentration among ESCC patients. According to our results, COX-2 mRNA and protein and subsequently PGE2 were increased in the majority of ESCC patients and may be involved in carcinogenesis. Although serum PGE2 level significantly increased in patients but ROC curve analysis showed it cannot be a power biomarker. Therefore, it can be used as a complementary diagnostic marker for cancer.

\section{Conclusions}

In the present study, we found a significant association between 8473TC genotype and risk of ESCC. Furthermore, there was an association between -1290AA, -765CC, 8473 (TC and CC) genotypes and COX2 expression as well PGE2 level in patients with ESCC. Therefore, carriers of these polymorphisms might be more susceptible to ESCC. However, further mechanistic researches are necessary to confirm our results.

\section{Conflict of interests}

The authors declare that there is no conflict of interests regarding the publication of this paper.

\section{References}

Abdel-Sattar, S. A. L., Ibrahim, H. A. F., \& El Sayed, H. A. E. (2018). Knowledge, Attitude and Practices of Working Women in Tabuk University Regarding Breast Cancer. International Journal of Pharmaceutical Research \& Allied Sciences, 7(3), 198-208.

Alkhatib, M. H., Alharbi, S. A., \& Mahassni, S. H. (2017). In Vivo Evaluation of The Anticancer Activity of The Docetaxel Incorporated Into Nanoemulsion Based on Orange Oil. Pharmacophore, 8(6), 41-47. 
Alshammari, F. D. (2018). Do Non-Viral Microorganisms Play a Role in the Aetiology of Human Cancers? A Review. International Journal of Pharmaceutical Research \& Allied Sciences, 7(4), 179-185.

Bab, S., Abdifard, E., Elyasianfar, S., Mohammadi, P., Mohammadi, E., Izadi, N., \& Heidari, M. (2018). Trend of the incidence of brain cancer in iran and it's 6 geographical regions during 2000-2005. Pharmacophore, 9(4), 41-52.

Bhandari et al. (2006). Prognostic significance of cyclooxygenase 2. BMC Cancer, 2, 1-9.

Cui, Y., Dong, C., Wu, B.-Q., Duan, X.-C., Shi, G., \& Gong, T. W. M. (2015). Expression of cyclooxygenase - 2, vascular endothelial growth factor, and epidermal growth factor receptor in Chinese patients with esophageal squamous cell carcinoma. Journal of Cancer Research and Therapeutics, 11, C44-8.

Dai, Y., Wu, Y., \& Li, Y. (2015). Genetic association of cyclooxygenase-2 gene polymorphisms with Parkinson's disease susceptibility in Chinese Han population. Int J Clin Exp Pathol, 8, 13495-13499.

Dasdemir et al. (2013). Cox-2 gene variants in migraine. Gene. Elsevier B.V., 518(2), 292-295.

Diakowska et al. (2014). Increased level of serum prostaglandin-2 in early stage of esophageal squamous cell carcinoma. Archives of Medical Science, 10(5), 956-961.

Expression et al. (2002). Artherosclerosis Common Promoter Variant in Cyclooxygenase-2 Evidence of Role in Acute-Phase Inflammatory Response. Arterioscler Thromb Vasc Biol, 22, 1631-1636.

Fawzy et al. (2013). Cyclooxygenase-2 $169 \mathrm{C}>\mathrm{G}$ and $8473 \mathrm{~T}>\mathrm{C}$ gene polymorphisms and prostaglandin E2 level in breast cancer: A case - control study. Gene. Elsevier B.V., 527(2), 601-605.

Fritsche et al. (2001). Functional Characterization of Cyclooxygenase-2 Polymorphisms, 299(2), 468-476.

Greenhough, A., Smartt, H. J. M., Moore, A. E., Roberts, H. R., Williams, A. C., \& Cancer. (2009). The COX-2/PGE 2 pathway: Key roles in the hallmarks of cancer and adaptation to the tumour microenvironment. Carcinogenesis, 30(3), 377-386.

Hambek et al. (2007). Inverse Correlation Between Serum Pge2 And T Classification In Head And Neck Cancer. Wiley Inter Science, 244-248.

Hemashree, J., \& Thangavelu, L. (2018). Anti - Inflammatory action of Acacia Catechu seed extract. Journal of Advanced Pharmacy Education \& Research, 8(3), 92-95.

Hoff, J. H., te Morsche, R. H. M., Roelofs, H. M. J., van der Logt, E. M. J., Nagengast, F. M., \& Juliët. (2009). COX-2 polymorphisms $-765 \mathrm{G} \rightarrow \mathrm{C}$ and $-1195 \mathrm{~A} \rightarrow \mathrm{G}$ and colorectal cancer risk. World J Gastroenterol, 15, 4561-4565.

Hu et al. (2005). A common polymorphism in the 3 UTR of cyclooxygenase 2 / prostaglandin synthase 2 gene and risk of lung cancer in a Chinese population. Lung Cancer, 48, 11-17.

Hu et al. (2016). High expression of cyclooxygenase 2 is an indicator of prognosis for patients with esophageal squamous cell carcinoma after Ivor Lewis esophagectomy. Thoracic Cancer I, 7, 310-315.

Cok, S. J., \& Morrison, A. R. (2001). The 3'-untranslated region of murine cyclooxygenase-2 contains multiple regulatory elements that alter message stability and translational efficiency. Journal of Biological Chemistry, 276(25), 23179-23185.

Kalinski, P., \& Alerts, E. (2012). Regulation of Immune Responses by Prostaglandin E 2. The Journal of Immunology, 188, 21-28.

Kosaka et al. (1994). Characterization of the human gene (PTGS2). Eur. J. Biochem, 897, 889-897.

Kuo, K.-T., Wang, H.-W., Chou, T.-Y., Hsu, W.-H., Hsu, H.-S., Lin, C.-H., \& Wang, L.-S. (2009). Prognostic Role of PGE2 Receptor EP2 in Esophageal Squamous Cell Carcinoma. Ann Surg Oncol, 6, 352-360.

Liang et al. (2011). Cyclooxygenase-2 Polymorphisms and Susceptibility to Esophageal Cancer: A Meta-Analysis. Tohoku J. Exp. Med., 223, 137-144.

Liu et al. (2006). Genetic Variants in Cyclooxygenase-2: Expression and Risk of Gastric Cancer and Its Precursors in a Chinese Population. Gastroenterology. AGA Institute American Gastroenterological Association, 130, 1975-1984.

Liu et al. (2008). COX-2 mRNA expression in esophageal squamous cell carcinoma (ESCC) and effect by NSAID. Diseases of the Esophagus, 21, 9-14. 
Liu et al. (2017). Association of Single Nucleotide Polymorphisms in the Prostaglandin-Association of Single Nucleotide Polymorphisms in the Prostaglandin-endoperoxide Synthase 2 (PTGS2) and Phospholipase A 2 Group IIA (PLA2G2A) Genes with Susceptibility to Esophageal. Asian Pacific Journal of Cancer Prevention, 2(81402689).

Lowry, M. C., Reynolds, J. V., \& Cathcart, M. (2014). The Role of PGE2 and its Corresponding Receptors (Ep1-4) in Oesophageal Carcinogenesis: Novel Therapeutics for Chemoprevention and / or Intervention. Carcinogenesis \& Mutagenesis, 5(3), 1000181.

Morgan, G. (1997). Deleterious effects of prostaglandin E2 in oesophageal carcinogenesis. Medical Hypotheses, 48(May 1996), 177-181.

Schmittgen, T. D., \& Livak, K. J. (2008). Analyzing real-time PCR data by the comparative C T method. Nature Protocols, 3(6), 1101-1108.

Smyth et al. (2017). Oesophageal cancer. Nature Publishing Group. Macmillan Publishers Limited, 3, 1-21.

Sommerfelt et al. (2015). Cytosolic Phospholipase A2 Modulates TLR2 Signaling in Synoviocytes. PLOSONE, April, 1-17.

Sundus, A., Ismail, N. E., \& Gnanasan, S. (2018). Exploration of healthcare practitioner's perception regarding pharmacist's role in cancer palliative care, malaysia. Pharmacophore, 9(4), 1-7.

Szczeklik, W., Sanak, M., \& Szczeklik, A. (2004). Functional effects and gender association of COX-2 gene polymorphism G -765 C in bronchial asthma. J Allergy Clin Immunol, 114, 248-253.

Tazawa, R., Ming, K. K. W. X., \& L.-H. W. (no date). Chracteristion of the genomic structure (pp. 190-199).

Upadhyay et al. (2009). Functional polymorphisms of cyclooxygenase-2 (COX-2) gene and risk for esophageal squmaous cell carcinoma. Mutation Research - Fundamental and Molecular Mechanisms of Mutagenesis, 663(1-2), 52-59.

Whitehead, A., \& Crawford, D. L. (2005). Variation in tissue-specific gene expression among natural populations. Genome Biology, 6, R13.

Williams, C. S., Mann, M., \& Dubois, R. N. (1999). The role of cyclooxygenases in ammation, cancer, and development. Oncogene, 18, 7908-7916.

Wu et al. (2011). Association of Cyclooxygenase 2 Polymorphic Genotypes with Prostate Cancer in Taiwan. Anticancer Research, 31(226), 221-225.

Yu et al. (2008). E Series of Prostaglandin Receptor 2-Mediated Activation of Extracellular Signal-Regulated Kinase / Activator Protein-1 Signaling Is Required for the Mitogenic Action of Prostaglandin E 2 in Esophageal Squamous-Cell Carcinoma. The Journal of Pharmacology and Experimental Therapeutics, 327, 258-267.

Zhang et al. (2005). Identification of Functional Genetic Variants in Cyclooxygenase-2 and Their Association With Risk of Esophageal Cancer xuemei. Gastroenterology, 129, 565-576.

Zhi et al. (2006). Significance of COX-2 expression in human esophageal squamous cell carcinoma. Carcinogenesis, 27, 1214-1221.

Zhi, H., Zhang, J., Hu, G. X., Lu, J. Y., \& Wang, C. Z. X. Q. (2003). The Deregulation Of Arachidonic Acid Metabolism-Related Genes In Human Esophageal Squamous Cell Carcinoma. Int. J. Cancer, 333(December 2002), 327-333.

\section{Copyrights}

Copyright for this article is retained by the author(s), with first publication rights granted to the journal.

This is an open-access article distributed under the terms and conditions of the Creative Commons Attribution license (http://creativecommons.org/licenses/by/4.0/). 